\title{
Responding to COVID-19: How to Navigate a Public Health Emergency Legally and Ethically
}

\author{
Lawrence O. Gostin \\ Georgetown University - Law Center - O'Neill Institute for National and Global Health Law, \\ gostin@law.georgetown.edu \\ Eric A. Friedman \\ O'Neill Institute for National and Global Health Law, Georgetown University Law Center, \\ eaf74@law.georgetown.edu \\ Sarah A. Wetter \\ Arizona State University Sandra Day O'Connor College of Law, sarah.wetter@asu.edu
}

This paper can be downloaded free of charge from:

https://scholarship.law.georgetown.edu/facpub/2255

https://ssrn.com/abstract=3579094

Lawrence O. Gostin, Eric A. Friedman \& Sarah Wetter, Responding to COVID-19: How to Navigate a Public Health Emergency Legally and Ethically, Hastings Center Report (March 26, 2020)

This open-access article is brought to you by the Georgetown Law Library. Posted with permission of the author. Follow this and additional works at: https://scholarship.law.georgetown.edu/facpub

Part of the Health Law and Policy Commons, Legal Ethics and Professional Responsibility Commons, and the Public Health Commons 


\section{ESSAYS}

\section{Responding to COVID-19: How to Navigate a Public Health Emergency Legally and Ethically}

by LAWRENCE O. GOSTIN, ERIC A. FRIEDMAN, and SARAH A. WETTER

$\mathrm{F}$ ew novel or emerging infectious diseases have posed such vital ethical challenges so quickly and dramatically as the novel coronavirus SARS-Cov-2, which causes COVID-19. SARS-CoV-2 is thought to have originated in a wet market in Wuhan, China, in early December, making a zoonotic leap from a bat (through an animal intermediary) to a human. It rapidly spread throughout China with highly efficient humanto-human transmission and has now circumnavigated the globe, with a foothold in every continent except Antarctica. The World Health Organization declared a public health emergency of international concern and recently classified COVID-19 as a worldwide pandemic.

As of this writing, the epidemic peak has not yet been reached in the United States, but community transmission is widespread. President Trump declared a national emergency as fifty governors declared state emergencies $^{1}$ - a situation unprecedented in modern America. In the coming weeks, hospitals will become overrun, stretched to their capacities.

Widespread social separation is rapidly becoming the norm, with closures of schools and universities, telecommuting, bans on large gatherings, and millions of people isolated in their homes or makeshift facilities. Bans on international travel are already pervasive. Domestic travel restrictions are exceedingly rare but now within the realm of possibility. Officials are even ordering cordon sanitaires (guarded areas where people may not enter or leave), popularly described as "lockdowns" or mass quarantines. For example, San Francisco recently ordered a

Lawrence O. Gostin, Eric A. Friedman, and Sarah Wetter, "Responding to COVID-19: How to Navigate a Public Health Emergency Legally and Ethically," Hastings Center Report 50 (2020): 1-5. DOI: 10.1002/ hast. 1090 lockdown, with other cities and states closing gathering places (such as bars, restaurants, and movie theaters) and advising residents to shelter in place.

When the health system becomes stretched beyond capacity, how can we ethically allocate scarce health goods and services? How can we ensure that marginalized populations can access the care they need? What ethical duties do we owe to vulnerable people separated from their families and communities? And how do we ethically and legally balance public health with civil liberties?

\section{A Strained Health System: Surge Response, Triage, Ethical Allocation}

A surge of individuals exhibiting flu-like symptoms, Aalong with the "worried well," will undoubtedly stress the health system. Health facilities do not have the capacity to cope with the expected patient numbers: they lack enough critical care beds, ventilators, essential medicines, and personal protective equipment for health workers. N95 masks, a key tool to prevent respiratory infections, are in short supply. Scarcity of health resources not only places COVID-19 patients at risk but will also delay care for patients with urgent needs such as for cancer, diabetes, and heart disease - and even affect safe delivery for pregnant women. Disruptions to the health system will likely cause more deaths of persons with a variety of urgent health needs than of patients diagnosed with COVID-19. ${ }^{2}$

In times of crisis and with health systems facing scarcity, hospitals, with guidance from public authorities and professional bodies, must make hard decisions to best ensure optimal health outcomes and fair distribution. 
How can we avoid the scarcity dilemma? Where possible, every effort should be made to avoid the scarcity dilemma altogether. We are already trying to do that through strict physical distancing, which could flatten the epidemic curve and moderate demand on the health system. But since the United States is so late in its mitigation efforts, scarcity is likely to become a reality. What should we do? A World War II-type mobilization could ramp up the production of personal protective equipment, ventilators, and other essential supplies and equipment that could become scarce. The president should exercise his full authority under the Defense Production Act to mobilize industry to provide urgently needed resources. Regions experiencing limited levels of COVID-19 could lend equipment, and deploy first responders, to regions where health system capacity is strained. Retired health workers or trained health workers not presently practicing could return to service. With ample funding, leadership, and coordination, scarcity can be, if not entirely avoided, then at least mitigated. The president or governors could also call in the military, National Guard, or Army Corps of Engineers for assistance with logistics, supply chains, and even building clinics.

How can we ethically balance physicians' duties to patients and to the wider community? Standards of care ordinarily require physicians to meet the specific medical needs of their patients. But in a crisis, we may have to shift the standard of care to emphasize the needs of the community, ${ }^{3}$ while still providing the best possible individual-level care. This concept was encapsulated by the National Academy of Medicine as "crisis standards of care," defined as the "optimal level of care that can be delivered during a catastrophic event, requiring substantial change in usual health care operations." 4

In jurisdictions with declared public health emergencies, ${ }^{5}$ crisis standards of care provide a mechanism for reallocating staff, facilities, and supplies to meet population needs. To free up scarce medical resources, for example, hospitals could postpone nonemergency tests and procedures. In the areas hardest hit so far, like Seattle and New York, hospital administrators have been canceling or postponing electiveand even some more serious ${ }^{6}$ - surgeries.

To avoid harm, health agencies and organizations must plan now to implement crisis standards of care; they should not wait until the disease is widely detected in the community. Implementing crisis standards must be part of a systemwide approach in which all stakeholders, including health professionals and the public, participate in transparent decision-making. ${ }^{\text {? }}$

How can we ethically allocate scarce resources? Even with increased production and measures like postponing nonurgent medical procedures, there might still be too few health workers and critical care beds and not enough supplies and equipment. These resources must be allocated ethically. First and foremost is the need to protect health workers delivering care in the midst of the crisis, for without them and their extraordinary efforts, the entire health system would collapse. Along with ensuring that health workers are adequately trained in infection control, supplied with protective equipment, and provided vaccines once available, the health system should designate health workers a top priority for receiving scarce resources that are vital for their own protection, care, and treatment.

Second, beyond health workers, decisions about who is tested or who receives treatment must center on prevention of SARS-CoV-2 transmission (public health), protection of individuals at highest risk, meeting societal needs, and promoting social justice. Protecting public health may mean prioritizing resources for people in confined settings (such as homeless shelters, prisons, and nursing homes), where the virus can spread rapidly from person to person. Resources may need to be targeted to areas experiencing localized outbreaks to curb transmission and prevent hospitalizations. Groups at highest risks, such as older adults, people with compromised immune systems, and people with underlying conditions (such as heart or lung disease or diabetes) are another priority, as they are most likely to become seriously ill and die. Meeting societal necessity means protecting critical services, like public safety, fire protection, and sanitation, as well as producers and suppliers of essential goods and services, like food and medicine, as well as people who carry out critical public health functions. Even with mass closures during COVID-19, these services must continue, and people working in these areas should be priorities as well. Finally, social justice demands that needed supplies and countermeasures are distributed equitably, with steps to ensure that poorer and marginalized populations-segments of the population traditionally left behind, like people with disabilities and people of color-receive a fair distribution of scarce resources.

In addition to identifying specific groups that need special care, ethical distribution requires a fair process in deciding. To the extent possible, decision-making about the allocation of scarce resources in response to COVID-19 should include the public and be made in advance, and it must be transparent and based on clearly explained rationales that are grounded in scientific evidence related to transmission of the virus, morbidity and mortality, and other relevant considerations, such as those delineated above.

Fair distribution is not only a national issue. Globally, lower-income countries will face much more scarcity than wealthier states and, if COVID-19 takes hold, a higher burden of disease. The United States is ethically obligated to assist-even if this means reducing American stockpilesto maximally protect and equally value all human life. ${ }^{8}$ Vitally needed supplies like personal protective equipment and, when available, vaccines and treatments, must not be hoarded by wealthier countries or the countries where they happen to be manufactured. This is a matter not only of ethics but also of ensuring Americans' health. Even if we get COVID-19 well under control in the United States, new outbreaks here will be all but inevitable unless other countries do so as well. Imagine the global political fallout if mil- 


\section{We are all only as safe as the most vulnerable among us - both}

in the United States and globally. Equity and public health

go hand and hand.

lions of people died in sub-Saharan Africa, while availability of an effective vaccine saved those living in North America and Europe.

Access to the Health System: Protecting the Most Vulnerable

T Tigh costs, fear of discrimination, and fear of deportaI tion can make COVID-19 testing and treatment inaccessible for vulnerable populations, including under- and uninsured persons and immigrants, ${ }^{9}$ and this lack of access implicates both health and justice concerns. Governments must assure that COVID-19 testing and care, and vaccines and treatment once available, are free so that cost does not cause anyone to delay or avoid care. Health facilities should be enforcement-free zones for undocumented immigrants, spaces where they will not face any risk of being detained or deported. Further, hospitals and health departments must have staff members trained in and responsible for communicating with people who do not speak English or are members of vulnerable populations, like refugees and undocumented immigrants and those with impaired hearing or vision.

Special measures may be necessary to ensure that vulnerable populations have access to health care and can practice good hygiene. For example, public health agencies should provide supplies of hand sanitizer or hygiene kits to shelters and outreach workers to distribute to people who are homeless for use throughout the day. ${ }^{10}$ And authorities could direct or incentivize businesses to permit people who are homeless to use their toilets and washing facilities.

\section{Ethical Physical Distancing: Gaining the Public's Cooperation}

A mple evidence shows extreme COVID-19 risk in congregate settings such as cruise ships, nursing homes, prisons, churches, shelters, and dorms. In Washington state, at least twenty-seven COVID-19 deaths are linked to a single nursing home. ${ }^{11}$ Physical distancing measures, including closing public spaces (schools, childcare, workplaces, mass transit) and canceling public events (holiday celebrations, religious ceremonies, sports events, political rallies), are becoming widespread and could help reduce viral spread if they are implemented smartly, scientifically, and ethically.

In this unprecedented period of social separation, loneliness, emotional detachment, and disruptions to social and economic life will produce profound harms. Vital cultural practices such as faith-based services, family bonding, and social connectedness are vanishing from public life. We are also witnessing something all too common in disease epidemics-blaming "the other." Racial and ethnic discrimination, in this case against people of Asian, and especially Chinese, descent, may result from the spread of misinformation or sheer ignorance. Governments must be prepared to address these harms.

Protecting the most vulnerable among us. Sacrifice is necessary, but it must be part of a fair social compact: people should adhere to advice or even mandates for physical distancing, but governments, in turn, must ensure that their needs are met. For the well-off, with well-stocked pantries and generous telework or paid leave, staying home may be feasible. But for poorer families and individuals, physical distancing can be harmful if they are cut off from sources of income, assistance, and support. Once out of work, individuals may not be able to afford necessities like food, housing, and medicine. With many schools closed across the United States, parents without paid family leave will struggle to find childcare and to provide meals that children would normally receive at school. For people who are elderly or with physical or mental disabilities, ordering food online or going to the grocery store can be difficult or impossible.

Where compliance with physical distancing is directly at odds with meeting basic needs, societal harms are inevitable and must be mitigated. Governments must provide wraparound medical care for the under- and uninsured and meet essential needs like medication, food, and water. If schools are closed, leaving low-income children without school breakfasts and lunch, authorities should arrange for children and families to receive food at home. ${ }^{12}$ Paid sick leave should be afforded to people temporarily out of work due to quarantines, isolation, business closures, or lack of childcare. ${ }^{13}$ People with disabilities and their caregivers should receive funding to ensure that their needs are met and to cover extra costs, such as for home delivery of food and other necessities. ${ }^{14}$ If Americans are doing their part to stay home and prevent COVID-19 transmission, government must do its part, too. That is an essential part of the social bargain.

Further, physical distancing may be very difficult in some places, such as in prisons, detention centers, homeless shelters, and nursing homes. We must protect against disease outbreaks at these sites, including ensuring good medical care, sanitary facilities, and good hygiene (such as ample supplies of soap and hand sanitizer). Large-scale and immediate use of compassionate release programs can protect 
nonviolent prisoners, especially if they are elderly or vulnerable, without compromising public safety. ${ }^{15}$ Other action will be needed, too, to prevent prisons and jails from becoming hotbeds of infection. Such actions might include releasing people with electronic monitoring (allowing for freedom of movement), ${ }^{16}$ releasing people who are jailed simply because they cannot pay bail, and reducing arrests and delaying sentencing. ${ }^{17}$ Those who have underlying medical conditions might be particularly good candidates for these measures. Some, like people who are at low risk of reoffending, might simply be released. And the government should enable people who are homeless and currently unsheltered to have safe shelter, whether procuring hotel rooms or developing emergency shelters designed to enable physical distancing.

Informed and trusted communication. Physical distancing policy must go hand in hand with informed and transparent public communication strategies. A trusted source of information must inform the public about known risks, unknown risks, and what steps are being taken to learn more. The public must be assured that their basic needs will be met and that strategies to mitigate harms, such as online instruction for elementary and secondary schools and broadcasting religious services, will be available. The public must be properly informed about good hygiene practices that can help prevent COVID-19's spread—and about how they can access hygiene products.

Isolation, Quarantine, Cordon Sanitaire, and Physical Distancing

G overnments seeking to limit the spread of COVID-19 may isolate sick individuals, quarantine exposed individuals, and institute cordon sanitaire. ${ }^{18}$ Isolation and quarantine were widely used in Asia and Canada during the SARS outbreak, but their effectiveness depends heavily on outbreak stage and viral transmission characteristics, which are not yet fully understood for SARS-Cov-2. These measures, where known or expected to be effective in reducing viral transmission, can be lawful, but infringements on individual privacy and liberties must be carefully considered.

Balancing public health and civil liberties. Quarantine, isolation, and cordon sanitaire are extreme measures that entail stringent restrictions on freedom of movement, association, and travel and can cause massive economic and social disruption. When balanced against public health interests, a basic rule is that governments should employ the least restrictive means necessary to protect public health. Meeting this standard requires that any COVID-19 isolation, quarantine, and cordon sanitaire must be based on rigorous scientific assessment of risk and effectiveness. Quarantine and isolation for COVID-19 should be ordered only if the person is known or highly suspected to have been exposed to the disease, and only for the maximum duration of incubation (fourteen days for COVID-19). Procedural due process requires that a person has proper notice and an opportunity to challenge a containment order, where feasible.
Further, individuals subject to isolation, quarantine, or cordon sanitaire orders must be assured a safe and habitable environment. Especially in large-scale quarantines, there could be challenges to ensuring safe and hygienic locations, medical and nursing care, necessities like food, water, and clothing, and communications. Vulnerable populations must be protected; authorities should identify in advance those who may need extra assistance (such as older people and people with disabilities) and develop plans to meet their needs. Above all, containment measures must not be a subterfuge for discrimination.

Deciding how far governments should go. Compulsory orders for quarantine, isolation, and cordon sanitaire bring enormous legal, ethical, and logistical challenges and should be used only as a last resort. Self-isolation or self-quarantine are preferable and generally effective. When properly informed, most people will follow their instincts to stay safe and will shelter in place at home. Self-isolation has another benefit besides limiting infringement on people's civil liberties: if hospitals become overwhelmed, as in South Korea and Italy, self-isolation for people with mild symptoms can help make more hospital beds available for sicker patients.

Where voluntary compliance is not an option, governments may need to enforce containment orders in the interest of public health, but how far should they go? It may be relatively easy to enforce isolation and quarantine orders against individuals who pose a known danger. Yet we are witnessing large-scale quarantines imposed without any individualized risk assessment. Elderly persons, for example, face such a high risk of death if they contract COVID-19 that many nursing homes have gone on "lockdown" mode, forbidding residents to leave or visitors to enter the facility. As described above, these orders must follow rigorous safeguards, including opting for the least restrictive alternative, depending on scientific assessment of risk and effectiveness, ensuring procedural due process, and providing a safe and habitable environment. Difficult questions will still arise, though. For example, are complete lockdowns necessary, or may an eighty-year-old without underlying conditions go for a short walk outside while practicing physical distancing?

Further, monitoring and enforcement through surveillance modes, including thermal scanners, electronic bracelets, and web cameras such as those used during the SARS outbreak, ${ }^{19}$ implicate privacy interests. Enlisting armed police and citizen informers to control large populations in cities like New York or Chicago seems so contrary to American values and the rule of law that it is difficult to conceive opting for that route in the days and weeks ahead. But San Francisco has already ordered its population to shelter in place for three weeks, with people directed to stay inside and avoid contact with others, though with numerous exceptions. People can leave their homes without government permission, but law enforcement has been asked to ensure compliance.

At a time of vast inequities, we are all only as safe as the most vulnerable among us-both in the United States and 
globally. If poor or disadvantaged members of our community cannot practice physical distancing or access health services, then we will all be at greater risk. Conversely, those who are better off should take measures to protect themselves from infection, both for their own health and in order to protect everybody else. Equity and public health go hand and hand. We are in uncharted territory, where vital human connections and economic activity are disrupted in ways not seen in generations. If we want to safeguard the public's health while being faithful to our most fundamental values, then we must ensure that our response is effective, ethical, and equitable.

1. L. O. Gostin, J. G. Hodge Jr., and L. F. Wiley, "Presidential Powers and Response to COVID-19," JAMA, March 18, 2020, doi:10.1001/jama.2020.4335.

2. K. J. Brolin Ribacke et al., "Effects of the West Africa Ebola Virus Disease on Health-Care Utilization-A Systematic Review," Frontiers in Public Health 4 (2016): 222; A. S. Parpia et al., "Effects of Response to 2014-2015 Ebola Outbreak on Deaths from Malaria, HIV/AIDS, and Tuberculosis, West Africa," Emerging Infectious Diseases 22, no. 3 (2016): 433-42.

3. D. Hanfling, B. M. Altevogt, and L. O. Gostin, "A Framework for Catastrophic Disaster Response,” JAMA 308 (2012): 675-76; N. Berlinger et al., Ethical Framework for Health Care Institutions and Guidelines for Institutional Ethics Services Responding to the Novel Coronavirus Pandemic (Garrison, NY: The Hastings Center, March 17, 2020), https://www.thehastingscenter.org/ethicalframeworkcovid $19 /$.

4. J. L. Hick et al., "Duty to Plan: Health Care, Crisis Standards of Care, and Novel Coronavirus SARS-CoV-2," a Discussion Paper, National Academy of Medicine, March 5, 2020.

5. L. O. Gostin and J. G. Hodge Jr., "US Emergency Legal Responses to Novel Coronavirus: Balancing Public Health and Civil Liberties," JAMA, February 13, 2020, doi:10.1001/jama.2020.2025.

6. K. Weise, M. Baker, and N. Bogel-Burroughs, "The Coronavirus Is Forcing Hospitals to Cancel Surgeries," New York Times, March 14, 2020.
7. Institute of Medicine, Committee on Guidance for Establishing Crisis Standards of Care for Use in Disaster Situations, Crisis Standards of Care: A Systems Framework for Catastrophic Disaster Response (Washington, DC: National Academies Press, 2012).

8. L. O. Gostin, "Pandemic Influenza: Public Health Preparedness for the Next Global Health Emergency," Journal of Law, Medicine, and Ethics 32 (2004): 565-73.

9. M. Jordan, “'We're Petrified': Immigrants Afraid to Seek Medical Care for Coronavirus," New York Times, March 18, 2020.

10. M. Taylor-Judd, "Pandemic Influenza: Public Health Preparedness for the Next Global Health Emergency," seattle.gov Human Interests Blog, March 2, 2020, at https://humaninterests.seattle.gov/2020/03/02/response-to-covid-19/.

11. M. Holcombe et al., "This Nursing Home Has Become the US Epicenter of the Coronavirus Outbreak, but Patients' Family Members Say They're Left in the Dark," CNN, March 9, 2020; R. Thebault, A. Hauslohner, and J. Dupree, "U.S. Coronavirus Death Toll Surpasses 100," Washington Post, March 17, 2020.

12. A. E. Yamin and R. Habibi, "Human Rights and Coronavirus: What's at Stake for Truth, Trust, and Democracy?" Health and Human Rights Journal, March 1, 2020, at https://www.hhrjournal. org/2020/03/human-rights-and-coronavirus-whats-at-stake-fortruth-trust-and-democracy/.

13. "We Are Ignoring One Obvious Way to Fight the Coronavirus," editorial, New York Times, March 3, 2020.

14. United Nations Human Rights, Office of the High Commissioner, "COVID-19: Who Is Protecting the People with Disabilities?-UN Rights Expert," press release, March 17, 2020.

15. J. Hatch, "The Only Way to Protect Elderly Prisoners from Coronavirus Is to Release Them," Huffington Post, March 16, 2020.

16. HumaneOutbreakResponse.org, "Humanity Not Cages: Demanding a Just and Humane Response to Outbreak," https://humaneoutbreakresponse.org, accessed March 19, 2020.

17. J. Rich, S. Allen, and M. Nimoh, "We Must Release Prisoners to Lessen the Spread of Coronavirus," Washington Post, March 17, 2020.

18. L. O. Gostin, "Public Health Strategies for Pandemic Influenza: Ethics and the Law," JAMA 295 (2006): 1700-1704.

19. Gostin, "Pandemic Influenza: Public Health Preparedness for the Next Global Health Emergency." 